ISSN (Print):1992-92 18, ISSN (Online):1992-92 18

DOI: https://doi.org/10.32792/utq/utjmed/19/1/8

\title{
Congenital Hiatal Hernia: A Surgical Approach
}

\author{
Dr. Jalal Jaafar Abdulhussein ( MBChB, FIBMS Thoracic and Cardiovascular \\ Surgery, FACS ) \\ Jalal.alzubaidy2015@gmail.com
}
Dr. Bahaa Ibrahim Hamza ( MBChB, FIBMS Thoracic and Cardiovascular Surgery, FACS )
Bahacom2006@yahoo.com

\author{
Dr. Sabah Hasan Salman (MBChB, Diploma in General Surgery ) \\ sabah1965s@yahoo.com
}

\begin{abstract}
Background : Congenital Hiatal Hernia is herniation of a viscus or a part of it through the esophageal hiatus to an intra-thoracic position.

Aim : To review our experience in surgical management of Congenital Hiatal Hernia in view of published literature .

Study design : Retrospective and Comparative.

Patients and Method : during a sixteen -year period (2000-2016) in a single thoracic surgery center, Detailed history taking and thorough physical examination were performed. The investigations included chest radiographs, contrast swallow studies, and rigid esophagoscopy mainly . Surgical techniques used to explore and repair hernia through laparotomy and left thoracotomy or both .

Results : Twenty-six cases of Congenital Hiatal Hernia were operated, in M:F ratio of (1.16:1), age range (25 days -6 years ) Mean age of presentation (1.84 Year) . Chief presenting symptoms werew frequent vomiting (20 patients), recurrent chest infections . The diagnosis depended primarily on contrast studies . Statistical analysis showed better outcome regarding hospitalization( 7.77 days compared with 9.125 ) and postoperative complication with Nissen procedure . 1 mortality included in this study caused by mediastinitis and septicemia .

Conclusion : Early recognition of Congenital Hiatal Hernia is of high importance in reducing postoperative complications and improving outcome . although SAGES guidelines / No. 8 / 2013 stated (Hiatal hernias can effectively be repaired by a transabdominal or transthoracic approach (++++, strong) ), Nissen fundoplication done to infant age group with excellent outcome , and our experience was better using Nissen fundoplication. The study recommend the need for carrying out a multicenter study on a national level., team management of Congenital Hiatal Hernia .

Key words : Congenital Hiatal Hernia, lower esophageal sphincter , Nissen fundoplication , Belsey Mark IV procedure .
\end{abstract}


ISSN (Print):1992-92 18, ISSN (Online):1992-92 18

DOI: https://doi.org/10.32792/utq/utjmed/19/1/8

\section{Introduction :}

Congenital hiatal hernia defined as herniation of a viscus or part of it through esophageal hiatus to intra-thoracic position . ${ }^{1}$.

\section{Background :}

First report of hiatal hernia was of Bright (1836), recorded autopsy of a girl aged 19 years with large portion of stomach was in thoracic cavity and the cardia was at level of T4 . 2 .

At the beginning of next century, the condition thought to be rare; With introduction and development of radiology Akerlund (1926) recognized that sliding hiatus hernia, in which cardia and part of stomach lie at varying distance above diaphragm, is common form of hernia and occurs frequently. 3.

The increase in intra-gastric pressure

produced may lead to prolapse of cardia into the chest especially at this period of development, the gastro-esophageal junction is probably not yet stabilized in its normal position.

\section{Investigations :}

Upper GI barium series is the preferred examination in the investigation of suggested hiatal hernia and its sequelae. ${ }^{4,5,6,7,8,9,10,11,12,13 \text {. }}$

\section{Radiography}

Most hiatal hernias found incidentally on routine chest radiographs. The hernia may be seen as retro-cardiac mass with or without air-fluid level. When air is seen within the hernia, stomach air bubble found below diaphragm tends to be absent.
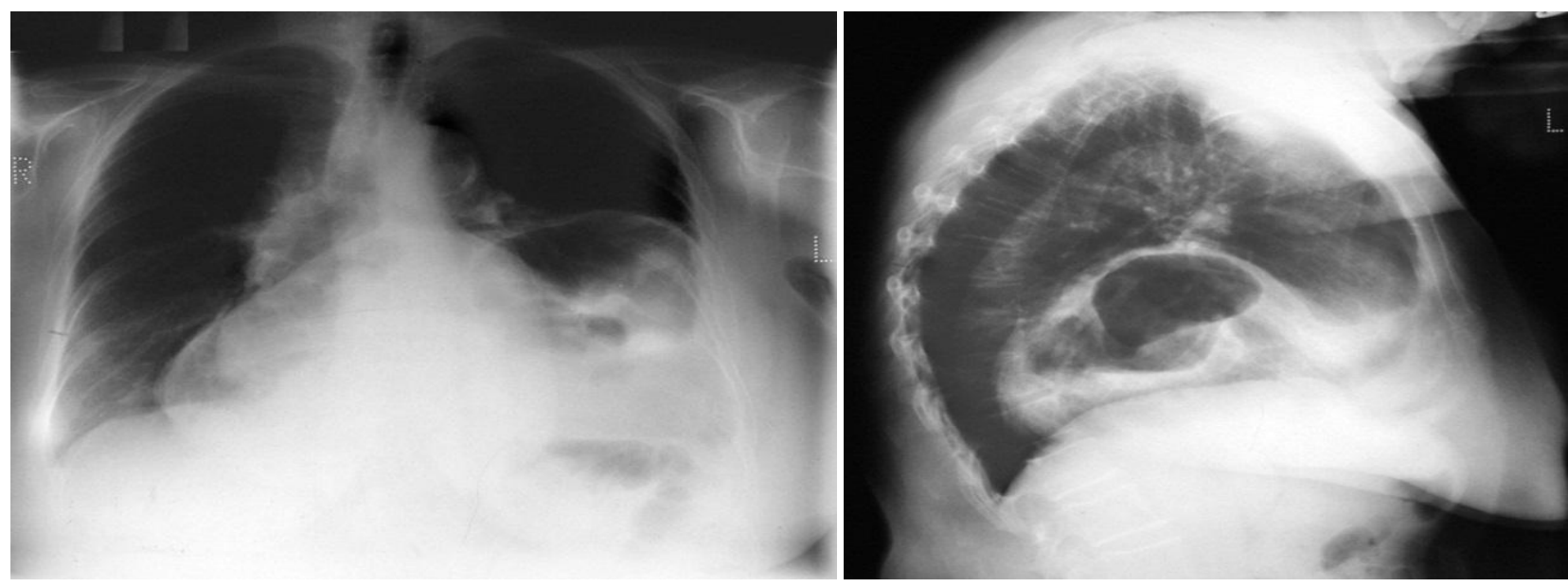

Fig. 1 : Frontal and lateral Chest Radiograph in patient with large hiatal hernia demonstrating retrocardiac opacity with radiolucent gas, which shifts mediastinum to the right. Source internet site : emedicine.medscape.com

\section{Upper GI barium series :}

Is the definitive method of diagnosing hiatal hernias (Fig.2). 
Web Site: https://jmed.utq.edu.iq

ISSN (Print):1992-92 18, ISSN (Online):1992-92 18

DOI: https://doi.org/10.32792/utg/utjmed/19/1/8

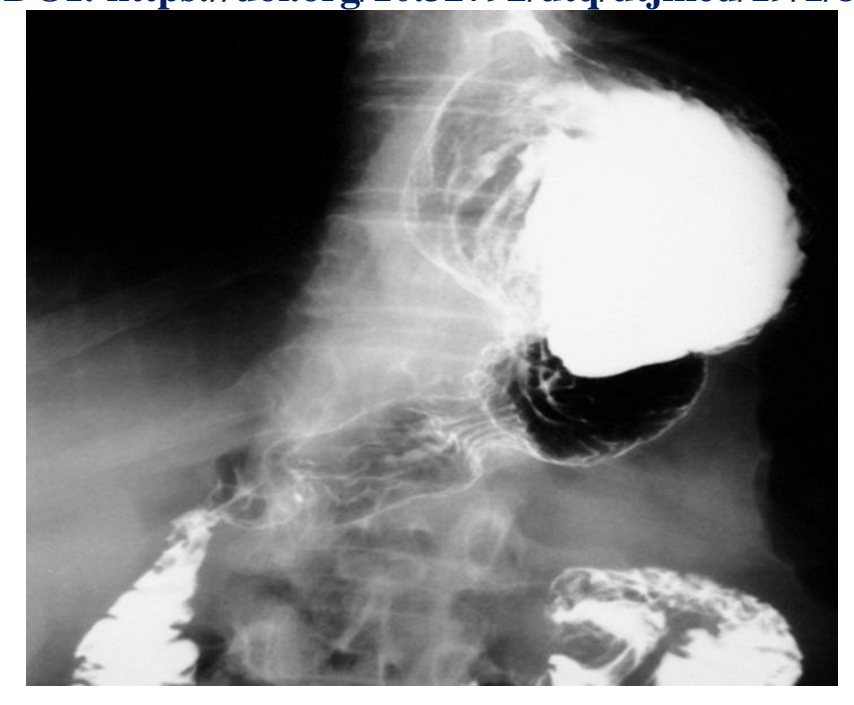

\section{Email:utjmed@utq.edu.iq}

Signs of sliding hiatal hernia in infants and young children include: intra-abdominal esophagus measuring less than $2 \mathrm{~cm}$, rounding of the gastro-esophageal angle, and presence of beak at the gastro-esophageal junction.

Fig. 2 : Barium-meal examination in patient with sliding hiatal hernia, demonstrates supradiaphragmatic location of gastro-esophageal junction. Source : internet site : emedicine.medscape.com

\section{Management :}

The principles of anti-reflux surgery are :

Restoration of intra-abdominal length of esophagus, It necessitates recognition of short esophagus and extensive esophageal mobilization to the aortic arch or by the addition of a Collis gastroplasty .

Reconstruction of esophageal hiatus requires complete mobilization of hiatal crura and careful removal of hernial sac.

Reinforcement of Lower esophageal sphincter done by construction of fundoplication, either total or partial.

\section{Surgery :}

\section{A laparoscopic, trans-abdominal approach}

Is preferred in most patients, except when shortened esophagus is present. The trans-abdominal approach is recommended for patients with coexisting abdominal disorder, prior thoracotomy, or severe respiratory disorder.

Nissen fundoplication: Consists of 360-degree fundic wrap via open or laparoscopic technique. It is the most commonly performed procedure for GER.

Toupet fundoplication: Consists of 270-degree posterior fundic wrap, with the wrapped segment sutured to crural margins and to anterolateral esophageal wall. 


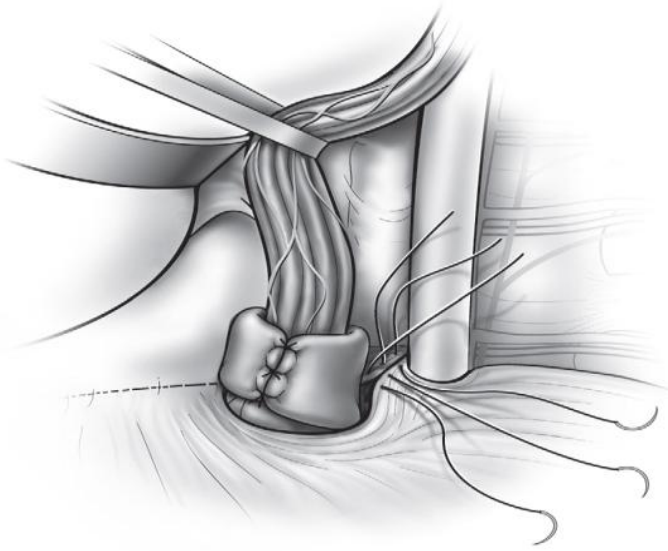

Fig. 3 : Partial fundoplication. Source : Pearson's Thoracic and Esophageal Surgery, 3rd Edition.

Pearson's Thoracic and Esophageal Surgery, 3rd Edition.

Fig. 4 : Nissen fundoplication. Source :

\section{Nissen fundoplication}

Can be done via a transthoracic approach, with results similar to those obtained with transabdominal approach

\section{A transthoracic approach}

Is recommended in patients with shortened esophagus or stricture, coexistent motor disorder, obesity, coexistent pulmonary lesion, or prior anti-reflux repair.

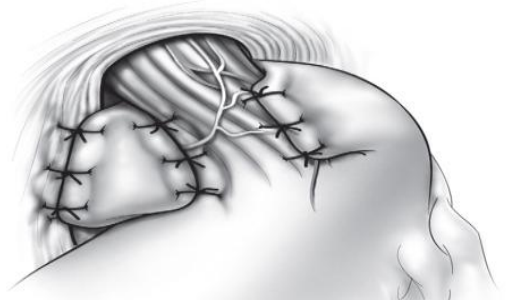

\section{Belsey Mark IV repair}

Consists of 270-degree anterior fundic wrap around $4 \mathrm{~cm}$ of distal esophagus.

\section{Collis gastroplasty}

a technique used to lengthen shortened esophagus. To minimize tension on anti-reflux repair, a gastric tube formed from the upper lesser curvature of stomach in continuity with distal 


\section{ISSN (Print):1992-92 18, ISSN (Online):1992-92 18 \\ DOI: https://doi.org/10.32792/utq/utjmed/19/1/8}

esophagus. Anti-reflux repair then constructed around the gastroplasty tube.

If anterior wrap (e.g., Thal, Dor) is to be performed, there is no need to disrupt the posterior attachments of esophagus. Dor and Thal fundoplications are created with the fundus folded over anterior aspect of esophagus. They are more commonly used in patients with achalasia after anterior myotomy has been performed. ${ }^{29,30,31,32}$

\section{New Anti-Reflux Trends : ${ }^{14,15}$}

Laparoscopic Magnetic ring operation restores the function of lower esophageal sphincter. It's Indications include Heartburn, Reflux, sphincter damage restricted to the abdominal portion of lower esophagus and a small hernia $(<3.0 \mathrm{~cm})$.

\section{Principle}

Augmentation of Anti reflux mechanism (lower esophageal sphincter) by placing magnetic ring around lower end of esophagus, which works as magnetic sphincter. In addition, the ring generates magnetic field, which is known to inhibit inflammation and pain .

\section{Transoral incisionless fundoplication (TIF) :}

An advanced endoscopic procedure that provide relief from acid reflux without surgery . an advantage of shorter operative time, less pain , and faster recovery . this procedure done with aid of an endoscope, fed by a special device preloaded with forceps ( tweezers ) and fasteners, and require no incision .

\section{Aim of the study:}

To review our experience in surgical management of congenital hiatal hernia comparing common surgical approaches .

\section{Patients and Method :}

Retrospective comparative study in single thoracic surgery center in baghdad, through sixteen years ( 2000-2016) in which 26 child with Congenital Hiatal Hernia admitted, operated .

\section{Preoperative assessment :}

All patients underwent basic hematological, biochemical investigations. Chest radiographs requested and contrast swallow study was investigation of choice for diagnosis . Large proportion of patients evaluated by preoperative rigid esophagoscopy to assess lower esophagus, site / function of cardia, and to exclude long-term complications of GERD, or other pathologies . Planning surgery created by surgical team composed of thoracic, pediatric surgeons in part of 


\section{ISSN (Print):1992-92 18, ISSN (Online):1992-92 18}

DOI: https://doi.org/10.32792/utq/utjmed/19/1/8

cases, and thoracic surgeon in rest along with anesthetist. All patients admitted to hospital, taking care of their nutrition and hydration status and given antibiotics preoperatively to treat their associated chest infections . severe anemia corrected preoperatively by blood transfusion .

\section{Surgical technique :}

Two surgical procedures used for correction of congenital hiatal hernia , most underwent Nissen fundoplication, Belsy mark IV .

\section{Statistical analysis :}

Including scope of $\boldsymbol{c h i}$ square was utilized to find significant association of morbidity and age of presentation and intervention. This relation was expressed as $\boldsymbol{p}$ value which was not significant when $\boldsymbol{p}$ value $>0.05$, and was significant when $\boldsymbol{p}$ value $<0.05$. The results calculated by using website Social Science Statistics.

\section{Results :}

In 16-years , (2000-2016), twenty-six patients with Congenital Hiatal Hernia diagnosed , admitted, operated at Ghazi Al-Hariri Hospital for surgical specializations, Baghdad . Fourteen male patients constituted $(53.84 \%)$ of cases, and remaining twelve patients $(46.16 \%)$ were females , M:F (1.16:1). Age range (25 days -6 years ). Mean age at presentation (1.84 Year) (22.08 Month) . Largest proportion of cases fall between 1-3 years (46\%) of total cases, as seen in the following chart .

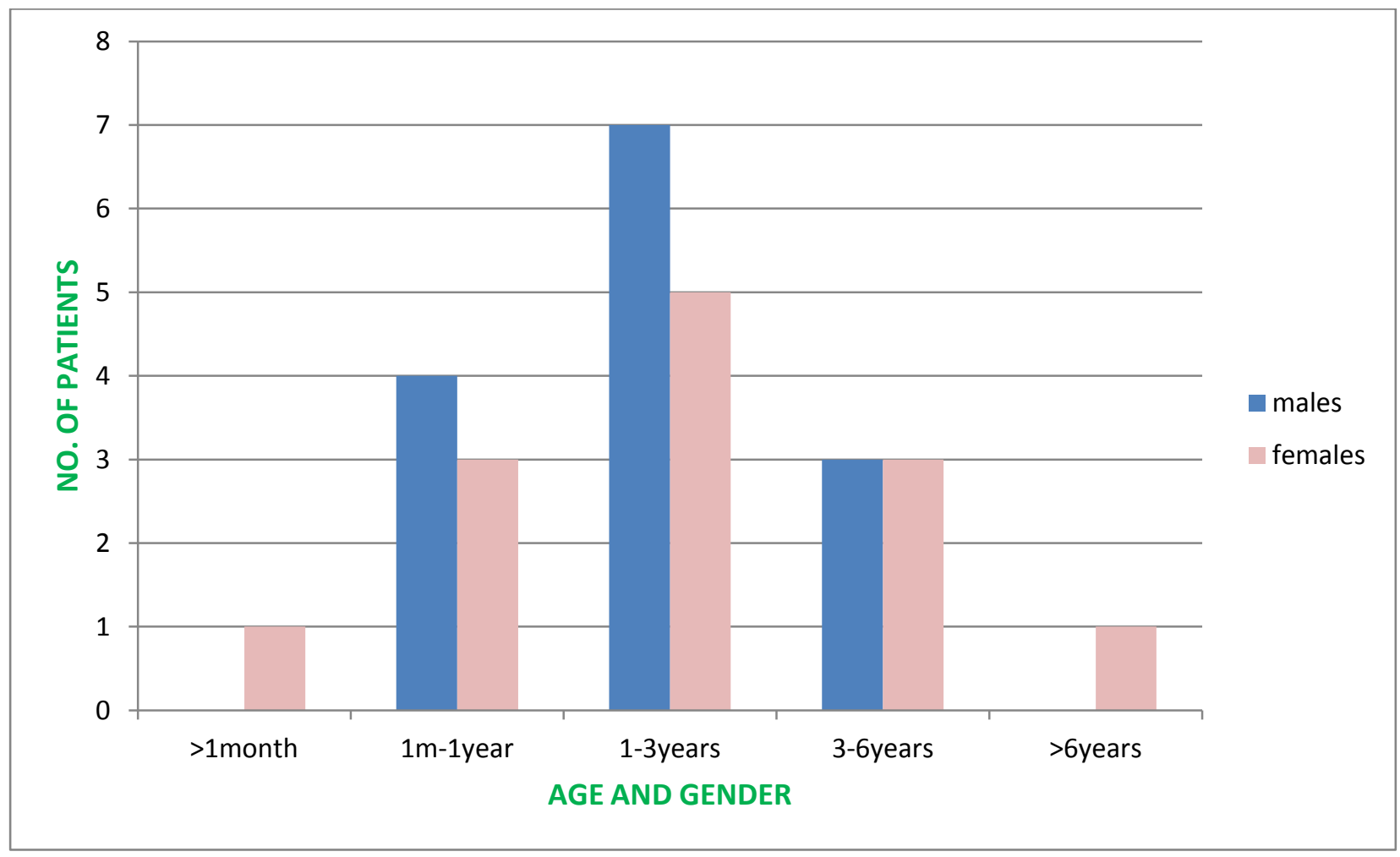


ISSN (Print):1992-92 18, ISSN (Online):1992-92 18

DOI: https://doi.org/10.32792/utq/utjmed/19/1/8

Figure 5 : Age and Gender distribution

Table 1 : comparison of children presenting at (1-3 years ) interval versus all other children age groups collectively and impact of this specific age group on the outcome of study .

\begin{tabular}{|l|l|l|l|}
\hline Age group / Outcome & Good & Complicated & Total \\
\hline $\mathbf{1 - 3}$ years & $\mathbf{7 ( 2 6 \% )}$ & $\mathbf{5 ( 1 9 \% )}$ & $12(46 \%)$ \\
\hline Other age groups & $\mathbf{1 3 ( 5 0 \% )}$ & $\mathbf{1}(\mathbf{3 \%})$ & $14(53 \%)$ \\
\hline Total & $\mathbf{2 0}(\mathbf{7 6 \%})$ & $\mathbf{6}(\mathbf{2 3 \%})$ & $26(100 \%)$ \\
\hline
\end{tabular}

Chi-square statistic calculated,$(=4.3385)$, the $p$-value is 0.03726 . which was significant.

In our study, as shown below, cases distributed in 3 groups of five years interval

Table 2 : incidence of presenting patients who underwent surgery in 5-year interval .

\begin{tabular}{|l|l|}
\hline Year & Number \\
\hline $\mathbf{2 0 0 0 - 2 0 0 5}$ & 8 \\
\hline $\mathbf{2 0 0 6 - 2 0 1 0}$ & 2 \\
\hline $\mathbf{2 0 1 1 - 2 0 1 6}$ & 16 \\
\hline Total & 26 \\
\hline
\end{tabular}

Chief presenting feature was frequent vomiting (76\%).was effortless regurgitation of undigested food or milk when child or infant laid down. This was followed by recurrent chest infections in $(60 \%)$, weight loss (56\%). Least presenting feature was hematemesis seen in 2 cases (8\%), associated with significant anemia. Shortness of breath resulted from increased pressure of herniated organs into thoracic cavity. On examination, some patients had signs of anemia (48\%) confirmed by laboratory investigations. Anemia was present in 12 patients some babies failed to achieve their optimal growth curve, This was seen in 8 cases $(32 \%)$.

Table 3 : Presenting symptoms and signs, number of patients and their percentage .

\begin{tabular}{|l|l|l|}
\hline Presentation & No. of cases & $\%$ \\
\hline Frequent vomiting & $\mathbf{2 0}$ & 76 \\
\hline Recurrent chest infections & $\mathbf{1 5}$ & 60 \\
\hline Weight loss & $\mathbf{1 4}$ & 56 \\
\hline Anemia & $\mathbf{1 2}$ & 48 \\
\hline Failure to thrive & $\mathbf{8}$ & 32 \\
\hline Shortness of breath & $\mathbf{7}$ & 28 \\
\hline Reflux & $\mathbf{7}$ & 28 \\
\hline Dysphagia & $\mathbf{3}$ & 12 \\
\hline Hematemesis & $\mathbf{3}$ & 11 \\
\hline
\end{tabular}

p-value was calculated and chi-square test used to see the impact of frequent vomiting and its consequences postoperatively, as shown in the following table : 
ISSN (Print):1992-92 18, ISSN (Online):1992-92 18

DOI: https://doi.org/10.32792/utq/utjmed/19/1/8

Table 4: Chi-square statistic : $0.2574, p$-value : 0.61193 . which was not significant.

\begin{tabular}{|l|l|l|l|}
\hline Symptomatology & Good & Complicated & Total \\
\hline Frequent vomiting mainly & $\mathbf{1 1}$ & $\mathbf{4}$ & 15 \\
\hline Other presentations & $\mathbf{9}$ & $\mathbf{2}$ & 11 \\
\hline Total & $\mathbf{2 0}$ & $\mathbf{6}$ & 26 \\
\hline
\end{tabular}

All patients sent for plain chest radiographs . Diagnosis depended (in 25 patients ) on contrast studies . Evidence of right intra-thoracic stomach , 10 cases, sometimes with absent left subdiaphragmatic gastric bubbles. CT scan was the method of diagnosis for a patient with severe dyspnea , and to exclude other pathologies . Esophagoscopy done to 16 patients $(61 \%)$ preoperatively, to aid diagnosis and planning of surgery, revealed intra-thoracic cardia ( 16 patients ), reflux esophagitis ( 5 patients ), incompetent cardia (6 patients ), and exclude other abnormalities ( e.g. : stricture ) ( 2 patients ).

Table 5 : workup of patients

\begin{tabular}{|l|l|l|}
\hline Technique & No. of patients & $\%$ \\
\hline CXR & $\mathbf{2 6}$ & 100 \\
\hline Contrast swallow & $\mathbf{2 5}$ & 96 \\
\hline Ultrasound & $\mathbf{1}$ & 4 \\
\hline CT scan & $\mathbf{2}$ & 8 \\
\hline MRI & $\mathbf{0}$ & 0 \\
\hline Esophagoscope & $\mathbf{1 6}$ & 61 \\
\hline
\end{tabular}

Our subject, two approaches ( laparotomy for Nissen fundoplication , left thoracotomy for Belsy Mark 4 procedure ), intra-operative findings of : widened hiatus through which identifiable sac herniated into chest. The sac arise from posterior parietal peritoneal cavity into thoracic extra pleural space. The main organ was stomach, and esophgogastric junction seen herniated into chest in all cases .

Post-operatively, 19 patients showed immediate post-operative improvement . 6 patients had recurrent symptoms, 4 patients after Nissen fundoplication , 2 patients after primary BMIV procedure, there was need for another procedure, after which 5 patients got better post-operative course . 2 patients needed admission and conservative treatment to treat single episode recurrence of symptoms, after which they both did well .

Table 6 : postoperative outcome of 26 patients with congenital hiatal hernia.

\begin{tabular}{|l|l|l|}
\hline Follow up & No. of patients & $\%$ \\
\hline Relief & $\mathbf{1 9}$ & 73 \\
\hline Recurrence + procedure & $\mathbf{6}$ & 23 \\
\hline Death & $\mathbf{1}$ & 3 \\
\hline Total & $\mathbf{2 6}$ & 100 \\
\hline
\end{tabular}


Thi-Qar Medical Journal (TQMJ): Vol.(19), No.(1), 2020

Web Site: https://jmed.utq.edu.iq

Email:utjmed@utq.edu.iq

ISSN (Print):1992-92 18, ISSN (Online):1992-92 18

DOI: https://doi.org/10.32792/utq/utjmed/19/1/8

Table 7 : Outcome for Nissen fundoplication

\begin{tabular}{|c|c|c|c|c|}
\hline No. & Age & Outcome & Second operation & Third operation \\
\hline 1 & $25 d$ & Good & & \\
\hline 2 & $5 \mathrm{~m}$ & Good & & \\
\hline 3 & $9 \mathrm{~m}$ & Good & & \\
\hline 4 & $10 \mathrm{~m}$ & Recurrence & BMIV & \\
\hline 5 & $11 \mathrm{~m}$ & Good & & \\
\hline 6 & $1 y$ & Good & & \\
\hline 7 & $1 y$ & Good & & \\
\hline 8 & $1 y$ & Good & & \\
\hline 9 & $1 y$ & Recurrence & BMIV & \\
\hline 10 & $1.2 \mathrm{y}$ & Recurrence & BMIV & \\
\hline 11 & 1.4 & good & & \\
\hline 12 & $1.7 \mathrm{y}$ & Recurrence & Redo / nissen & Ivor lewis esoph. \\
\hline 13 & $2 y$ & Good & & \\
\hline 14 & $2 y$ & Good & & \\
\hline 15 & $3 y$ & Good & & \\
\hline 16 & $3 y$ & Good & & \\
\hline 17 & $3.6 \mathrm{y}$ & Good & & \\
\hline 18 & $4 y$ & Good & & \\
\hline 19 & $4 y$ & Good & & \\
\hline 20 & $5 y$ & Good & & \\
\hline 21 & $6 y$ & Good & & \\
\hline
\end{tabular}

BMIV was done to 3 of recurrent Nissen cases, and to 5 other patients primarily.

Table 8 : Outcome of BMIV operation .

\begin{tabular}{|l|l|l|l|}
\hline No. & Age & Outcome & Notes \\
\hline $\mathbf{1}$ & $\mathbf{4} \mathbf{~ m}$ & Recurrence & Stenosis/ esophagoscopic dilatation \\
\hline $\mathbf{2}$ & $\mathbf{1 0} \mathbf{~ m}$ & Good & Post Nissen \\
\hline $\mathbf{3}$ & $\mathbf{1} \mathbf{y}$ & Good & Post Nissen \\
\hline $\mathbf{4}$ & $\mathbf{1 . 2} \mathbf{y}$ & Good & Post Nissen \\
\hline $\mathbf{5}$ & $\mathbf{1 . 3} \mathbf{y}$ & Good & \\
\hline $\mathbf{6}$ & $\mathbf{1 . 4} \mathbf{y}$ & Good & Mediastinitis, septicemia \\
\hline $\mathbf{7}$ & $\mathbf{1 . 6} \mathbf{y}$ & Death & \\
\hline $\mathbf{8}$ & $\mathbf{3} \mathbf{y}$ & Good & \\
\hline
\end{tabular}


Thi-Qar Medical Journal (TQMJ): Vol.(19), No.(1), 2020

Web Site: https://jmed.utq.edu.iq

Email:utjmed@utq.edu.iq

ISSN (Print):1992-92 18, ISSN (Online):1992-92 18

DOI: https://doi.org/10.32792/utq/utjmed/19/1/8

Table 9 : Chi-square test comparing significance of results of both procedures , $p$-value $=$ 0.004607 which is significant .

\begin{tabular}{|l|l|l|}
\hline & Good & Complicated \\
\hline Nissen & 17 & 4 \\
\hline BMIV & 6 & 2 \\
\hline Total & 23 & 6 \\
\hline & & \\
\hline
\end{tabular}

Table 10 : Hospitalization

Mean time hospitalization for patients was (3.36) days pre-operatively , (0.32) day at RCU , and

\begin{tabular}{|c|c|c|c|c|}
\hline Patient no. & Preop (days) & RCU (days) & Postop (days) & Total (days) \\
\hline 1 & 1 & 0 & 5 & 6 \\
\hline 2 & 4 & $\mathbf{0}$ & 8 & 12 \\
\hline 3 & 1 & 0 & 7 & 8 \\
\hline 4 & 3 & 0 & 5 & 8 \\
\hline 5 & 8 & 4 & 8 & 20 \\
\hline 6 & 6 & $\mathbf{0}$ & 3 & 9 \\
\hline 7 & 1 & 0 & 6 & 7 \\
\hline 8 & 10 & 0 & 4 & 14 \\
\hline 9 & 4 & 0 & 4 & 8 \\
\hline 10 & 3 & 1 & 3 & 7 \\
\hline 11 & 3 & 1 & 3 & 7 \\
\hline 12 & 3 & 0 & 2 & 5 \\
\hline 13 & 3 & 0 & 9 & 12 \\
\hline 14 & 1 & 0 & 4 & 5 \\
\hline 15 & 4 & $\mathbf{0}$ & 9 & 13 \\
\hline 16 & 1 & $\mathbf{1}$ & 4 & 6 \\
\hline 17 & 13 & 0 & 3 & 16 \\
\hline 18 & 2 & 0 & 6 & 8 \\
\hline 19 & 1 & $\mathbf{0}$ & 3 & 4 \\
\hline 20 & 1 & 0 & 4 & 5 \\
\hline 21 & 5 & 0 & 2 & 7 \\
\hline 22 & 1 & $\mathbf{0}$ & 5 & 6 \\
\hline 23 & 3 & 0 & 3 & 6 \\
\hline 24 & 1 & 1 & 3 & 5 \\
\hline 25 & 1 & 0 & 8 & 9 \\
\hline 26 & 2 & 0 & 4 & 6 \\
\hline mean & 3.30 days & 0.32 days & 4.80 days & 8.42 days \\
\hline
\end{tabular}

(4.84) days post-operatively. Hospitalization was slightly longer in Belsy Mark IV procedure (9.125) days compared with Nissen ( 7.77) days. Four patients admitted to the RCU for follow up, 3 were discharged next day, 1 kept due to deteriorating condition caused by mediastinitis and septicemia, unfortunately died . 
ISSN (Print):1992-92 18, ISSN (Online):1992-92 18

DOI: https://doi.org/10.32792/utq/utjmed/19/1/8

\section{Discussion :}

Published researches discussed uncommon varieties and complications besides possible familial associations. We focused our attention at patients who needed surgical intervention at different ages and presentation ; complicated hiatal hernia with intra-thoracic transverse colon and spleen, hiatal hernia with delayed gastric emptying , and , uncommon right intra-thoracic stomach.

\section{Incidence :}

Table 11: Comparison with total operated cases / duration of different studies

\begin{tabular}{|c|c|c|c|c|}
\hline Study & Year & No. of patients & $\begin{array}{c}\text { Duration of } \\
\text { study }\end{array}$ & Incidence \\
\hline J randolph & 1974 & 72 & 15 & 4.8 \\
\hline Al salem & 2000 & 6 & 8 & 0.75 \\
\hline J karpelowsky et al & 2006 & 59 & 42 & 1.4 \\
\hline N jetley et al & 2009 & 9 & 10 & $\mathbf{0 . 9}$ \\
\hline WM Hussen & 2005 & 8 & 5 & $\mathbf{1 . 6}$ \\
\hline Our study & 2016 & 26 & 16 & $\mathbf{1 . 6}$ \\
\hline
\end{tabular}

Incidence of Hiatal Hernia varies greatly among institutions, and with progression of time and facilities . there are several possible reasons for this variation . geographical or regional differences seem an unlikely explanation, since the studies reporting high incidence of hiatal hernia are scattered regionally and internationally . difference in radiologic techniques is certainly a factor .

In our study, there was increasing number of operations on children with Congenital Hiatal Hernia so that the majority of operations was in the last 5 years (16/26 during 2011-2016 ). This could be related to better diagnosis of congenital hiatal hernia
Twenty-six cases reviewed through 16 years in this study, in single thoracic surgical center . this number compared to different studies as shown below, considered good, but more operated patients in children's hospital, Washington D.C. , was 72 infants in 15 years interval, this was attributed to the fact that the mentioned hospital was pediatric hospital with cooperation of pediatricians and pediatric surgeons ${ }^{1,18,19,20}$.
Age And Gender Distribution : There was slight male preponderance in $\mathrm{M}: \mathrm{F}$ ratio of 1.6:1, this met the ratio published by WM Hussen , AH Al-Salem , Mustafa imanoglu ${ }^{1,19,21}$. A 10 year study from a single Saudi center by NK Jetley, however, showed a $\mathrm{M}: \mathrm{F}$ ratio of $1: 2 .^{17}$

Age at presentation ranged 25 days -6 years , with mean ( 1.84 ) year, comparative to studies of AH Al-Salem, JS karpelowsky , series of 59 children underwent surgery, mean age at presentation was respectively : $1.3,1.95$ years.$^{19,18}$

Large number of children presented at 1-3 years age interval $(12,46 \%)$, together, with 


\section{ISSN (Print):1992-92 18, ISSN (Online):1992-92 18}

DOI: https://doi.org/10.32792/utq/utjmed/19/1/8

the most of post-operative complications ( 5 complicated cases form $83 \%$ of all complicated cases ) that were included in the same age interval, may be attributed to preoperative status of children who presented with the disease not responding to maximal medical therapy, positional therapy, besides comorbidities of weight loss, frequent respiratory infections, dehydration, failure to thrive, anemia, etc. .Second reason is the importance of early recognition and referral for surgery to prevent future morbidity and mortality . Comparison of children presenting at (1-3 years ) interval versus all other children age groups was significant when using chi-square test, may reinforce our claim .

Symptoms : Patients presented mainly with frequent vomiting $(20,76 \%)$, recurrent attacks of chest infections $(15,60 \%)$, weight loss, anemia This is compared with the presentations of subjects reported by $\mathrm{AH}$ alSalem ' J Randolph, JS Karpelowsky, with more children presented with vomiting as a chief presentation in this study. ${ }^{19,20,18}$

Table 12 : Comparison of chief presenting symptoms .

\begin{tabular}{|c|c|c|c|c|c|}
\hline $\begin{array}{c}\text { Chief presenting } \\
\text { symptom }\end{array}$ & J randolph & Al salem & $\begin{array}{c}\text { J karpelowsky et } \\
\text { al }\end{array}$ & $\begin{array}{c}\text { N jetley et } \\
\text { al }\end{array}$ & $\begin{array}{c}\text { Our } \\
\text { study }\end{array}$ \\
\hline Vomiting & $/$ & $50 \%$ & $40 \%$ & $55 \%$ & $76 \%$ \\
\hline $\begin{array}{c}\text { Respiratory tract } \\
\text { infection }\end{array}$ & $33.3 \%$ & $33 \%$ & $54 \%$ & $66 \%$ & $60 \%$ \\
\hline Anemia & $/$ & $/$ & $33 \%$ & $11 \%$ & $48 \%$ \\
\hline Failure to thrive & $48.6 \%$ & $/$ & $30 \%$ & $22 \%$ & $32 \%$ \\
\hline
\end{tabular}

Children presented with repeated vomiting did not necessarily experience complicated post-operative course, we calculated the p-value using chi-square test to compare children presented mainly with repeated vomiting with other children, to see the impact on the post-operative course, it was nonsignificant .

Diagnosis : We used chest radiographs and contrast swallow studies mainly, followed by esophagoscopy $(100 \%$, $96 \%, 61 \%$, respectively ) .rarely CT scan of chest and abdominal ultrasound . MRI is not used in our study.
Chest X- Ray Findings of a shadow obliterating right cardiac border, left hemi-diaphragm, retro-cardiac air fluid level. Evidence of right intra-thoracic stomach , 10 cases, sometimes with absent left sub-diaphragmatic gastric bubbles .

In Contrast Swallow Study : Contrast study

\section{Findings :}

1. Abnormally high position of gastroesophageal junction ,

2. Beak formation at gastric cardia ,

3. Irregularity of the cardia, 
ISSN (Print):1992-92 18, ISSN (Online):1992-92 18

DOI: https://doi.org/10.32792/utq/utjmed/19/1/8

4. Visualization of gastric folds above the diaphragm ,

5. Delayed gastro-esophageal reflux .These findings coincides with those published by WM Hussen, and analysis of radiologic findings of Congenital Hiatal Hernia , by DB Darling $1975^{1,22}$.

Preoperative Esophagoscope used in 16 patients $(61 \%)$. in some studies ,as in paper published by L D Hill, esophagoscopy used in all patients preoperatively

Surgical Treatment : Two approaches used to repair Congenital Hiatal Hernia depending on indications of surgery ( laparotomy for Nissen fundoplication ( 21 operations) , left thoracotomy for Belsy Mark 4 procedure (8 operations )) . Nissen fundoplication worked well in infant age group . J Randolph experience with nissen fundoplication met our study at this point ${ }^{20}$. No finding of congenital short esophagus reported in our study, this was supported by WM hussen by the ease of repositioning of herniated stomach to original position ${ }^{1}$.

Comparing the results of two procedures, Our experience was better with Nissen fundoplication ( tables 7,8) . Recurrence percenatages were $19 \%$ compared with $25 \%$ of BMIV operation .This was statistically significant using chi-square method ( $\mathrm{p}$-value $=0.004)$. In addition, the hospitalization time was slightly longer when using BMIV operation .

\section{Morbidity :}

GOOD OUTCOME defined as complete elimination of reflux, demonstrated by radiological studies, and symptomatic relief . COMPLICATED CASES who needed another procedure .There was 6 complicated cases , with total percentage of $23 \%$. this was lower when weighed against JS karpelowsky study of 59 children with $27 \%$ recurrence . in reviewing our experience in nissen fundoplication in infant age group, we had 9 operated infants with two recurrences underwent further Belsy Mark IV operation with good post-operative course on long-term follow up .recurrence percentage was $11 \%$ versus $8 \%$ in Randolph series . ${ }^{20}$

MORTALITY : This study included one mortality, was an -18 month female, presented with severe vomiting, repeated chest infections since birth, weight loss, and failure to thrive. investigations showed anemia and high white cell count . diagnosis made by chest radiograph , contrast study , upper GI series . finding of big Hiatal Hernia , dilated esophagus , GERD II,III , lax cardia . approach via left thoracotomy, Belsy Mark IV procedure, post-operative fever and the patient looked ill and toxic . postoperative contrast showed leak into pleural cavity and slow passage of contrast distally . a second surgery needed to evacuate pus and insert a feeding jejunostomy tube . patient admitted to the RCU and died due to septicemia and multiple organ failure later on this made $3 \%$ as a mortality percentage, and was good compared to that of NK Jetley $(11 \%)^{17}$. mortality in infant age group underwent nissen fundoplication was zero compared to $4 \%$ in the study of $\mathrm{J}$ Randolph , reflecting good outcome. ${ }^{20}$

Follow up of our patients was much difficult . poor contact with patients, lost medical records (2006-2008) , poor documentation limit our activity . in 17 children, immediate resolution of symptoms occured . 6 needed a second procedure : 4 underwent additional Belsy Mark IV surgery , one needed additional redo operation one 
year later (nissen ) , Ivor Lewis esophagectomy ,then feeding jejunostomy, and the last needed esophagoscopy and dilatation . all did well till present time . 2 cases readmitted for recurrent symptoms did not require surgery, a 2 year old female with history of nissen fundoplication 6 months priorly, complained dysphagia , a 4 month female , readmitted 1 month later with frequent vomiting, treated conservatively, well responded till present time. One patient with post-operative failure of right lung to expand caused by atelectasis, preoperative chest infection . post-operative rigid bronchoscopy done to clear viscid secretions and aid total lung expansion.

Nissen fundoplication done to infant age group with excellent outcome, and our experience was better using Nissen fundoplication. The study recommend the need for carrying out a multicenter study on a national level., team management of Congenital Hiatal Hernia .

\section{References:}

1. Hussen WM , Al-Kawaz Shatha AA . Congenital Right Intra-thoracic Hiatal Hernia . the Iraqi post-graduate medical journal, vol.7 , No.1, 2008.

2. Bright, R. Guy's Hosp. Rep. (1836), 1, 398.

3. Akerlund, A. Acta radiol. (1926), 6, 3.

4. Lister , J. , Hiatus hernia in children , Postgraduate Medical Journal , August 1972 , 48, 501506.

5. Jawad AJ ; Al samarraie Al ,Almofala S et allCongenital PEHH in infancy Pediatric Surgery International $1998 ; 13,91-94$.

6. Kahrilas PJ, Kim HC, Pandolfino JE. Approaches to the diagnosis and grading of hiatal hernia. Best Pract Res Clin Gastroenterol. 2008. 22(4):601-16.

7. Halkiewicz F, Kasner J, Karczewska K, Rusek-Zychma M. Ultrasound picture of gastroesophageal junction in children with reflux disease. Med Sci Monit. 2000 Jan-Feb. 6(1):969 .

8. Yamashita K, Tsunoda T. Three-dimensional computer images of stomach diseases. Am J Surg. 2002 Jan. 183(1):87-8. 


\section{ISSN (Print):1992-92 18, ISSN (Online):1992-92 18}

DOI: https://doi.org/10.32792/utq/utjmed/19/1/8

9. Khouzam RN, Akhtar A, Minderman D, Kaiser J, D'Cruz IA. Echocardiographic aspects of hiatal hernia: A review. J Clin Ultrasound. 2007 May. 35(4):196-203.

10. Barone M, Di Lernia P, Carbonara M, Ladisa R, Donno A, Amoruso A, et al. Sliding gastric hiatal hernia diagnosis by transabdominal ultrasonography: an easy, reliable and non-invasive procedure. Scand J Gastroenterol. 2006 Jul. 41(7):851-5.

11. Broucek JR, Ritter LA, Francescatti AB, Smith CH, Luu MB, Autajay KM, et al. Radiographic predictability of hiatal hernia prior to gastric band surgery. JSLS. 2014 Apr-Jun. 18 (2):243-5.

12. Le Page PA, Furtado R, Hayward M, Law S, Tan A, Vivian SJ, et al. Durability of giant hiatus hernia repair in 455 patients over 20 years. Ann R Coll Surg Engl. 2015 Apr. 97 (3):188-93.

13. Cakmakci E, Tahtabasi M, Celebi I, Cakmakci S, Bayram A, Tokgoz S, et al. Diagnostic significance of periesophageal fat pad in ultrasonography for sliding hiatal hernias: sonographic fat pad sign. Clin Imaging. 2014 Mar-Apr. 38 (2):170-3.

14. Becher A, Dent J. Systematic review: ageing and gastro-oesophageal Reflux disease symptoms, esophageal function and Reflux oesophagitis. Aliment Pharmacol Ther 2011; 33(4): 442-54.

15. Bonavina L, DeMeester T, Fockens $\mathrm{P}$ et al. Laparoscopic sphincter augmentation device eliminates Reflux symptoms and normalizes esophageal Acid exposure. Ann Surg 2010; 252(5): $857-862$

16. Hill LD . An Effective Operation for Hiatal Hernia: An Eight Year Appraisal. Annals of Surgery, October 1967, Volume 166 ,Number 4, pages : 681-690 .

17. Jetley N Kumar, Al-Assiri A Hassan, Al-Awadi Dawood . Congenital para-esophageal hernia : a 10 year experience from Saudi Arabia . indian J pediatr 2009 ; 76 (5): 489-493.

18. Karpelowsky JS, Weiselthaler N, Rode H. Primary para-esophageal hernia in children . Journal of pediatric surgery, September 2006, vol.41, issue 9, pages 1588-1593 .

19. Al-Salem AH . Congenital paraesophageal hernia in infancy and childhood . Saudi Medical Journal 2000; Vol. 21 (2): 164-167.

20. Randolph J, Lilly JR, Anderson KD. Surgical Treatment of Gastroesophageal Reflux in Infants . annals of surgery, Oct 1974 , Vol 180 , No. 4 , pages : 479-485 .

21. Mustafa imanoglu, Ali Cay, Polat Kosccu \& et all Congenital paraesophageal hiatal hernia ;pitfalls in the diagnosis and treatment , J.Pediatr.Surg. 2005 ;40, Issue 7 ,1128-1133.

22. Darling DB , Hiatal Hernia and gastroesophageal reflux in infancy and childhood, analysis of radiological findings . American Journal of Roentgenology. 1975;123: 724-736. 
ISSN (Print):1992-92 18, ISSN (Online):1992-92 18

DOI: https://doi.org/10.32792/utq/utjmed/19/1/8

\section{العلاج الجراحي للفتق الحجابي الولادي المنشأ}

الاكتور بهاء ابر اهيم حمزة

الاكتّور جلال جعفر عبدالحسين

الاكتور صباح حسن سلمان الخفي

انخاصة

المقدمة : فتق الفتحة الفؤادية الولادي يمكن ان يعرف بأنه انفتاق عضو بطني أو جزء منه خلال الفتحة

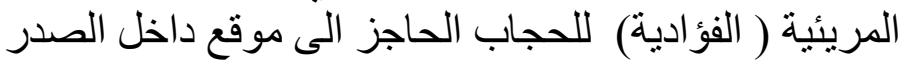

الهُف من البحث : لمر اجعة تجربتنا في الادارة الجراحية لفتق الفتحة الفؤادية الولادي في ضوء الدراسات الدولية المنشورة من البن

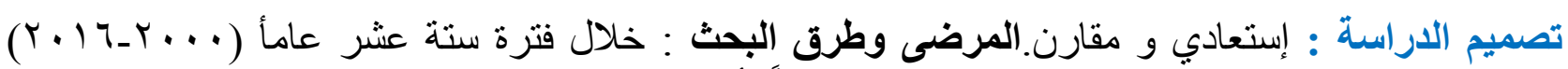

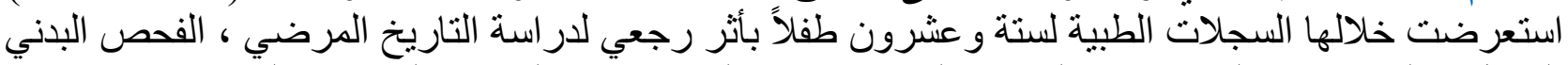

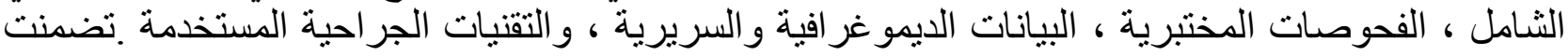

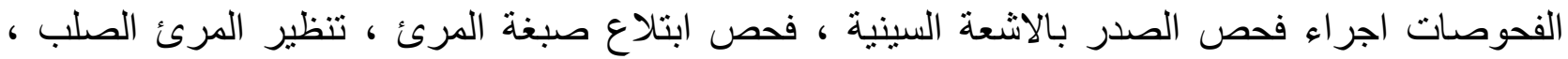

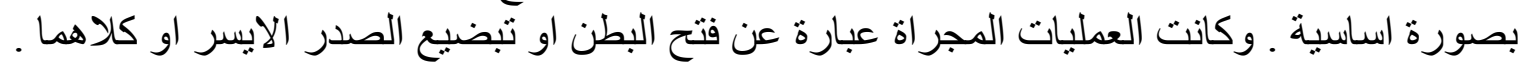

النتائج : ست و عشرون حالة من فتق الفتحة الفؤادية الو لادي عولجت جر احياً في مستشفى غازي الحريري

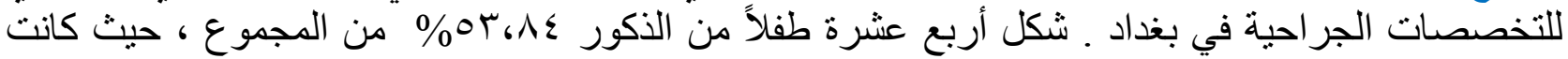

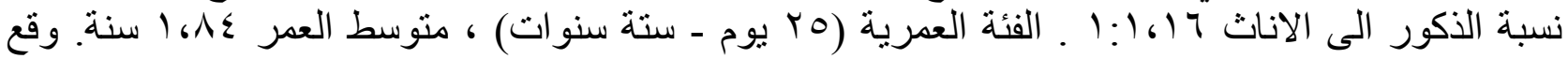

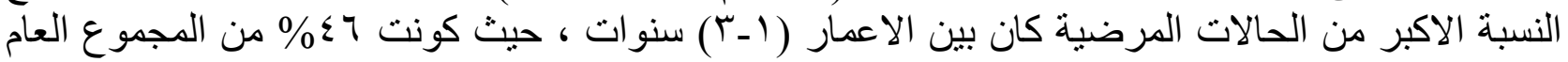

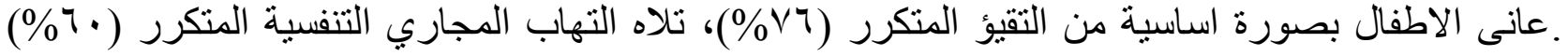

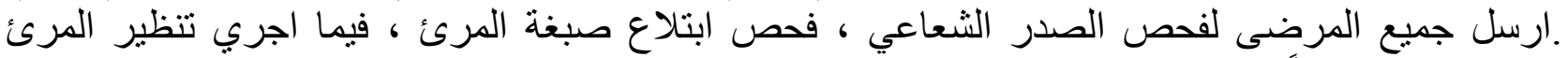

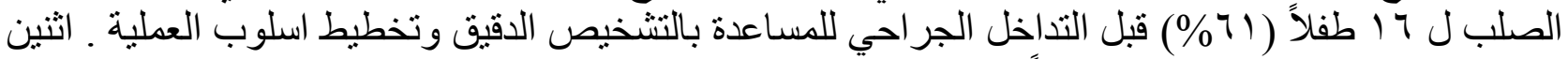

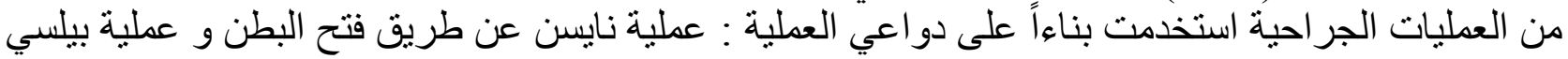

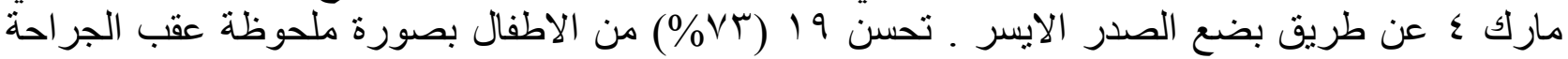

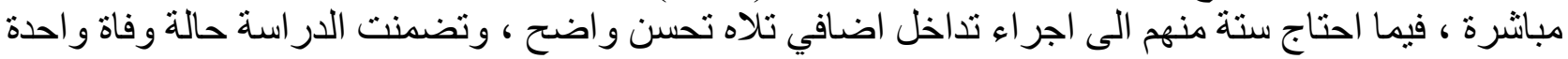

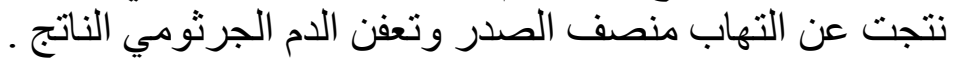

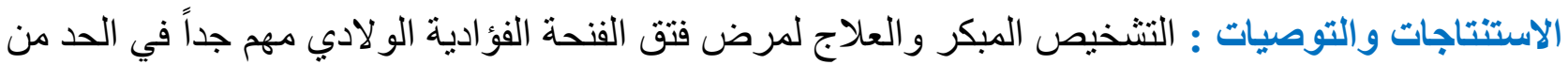

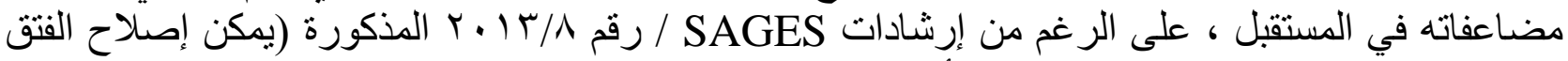

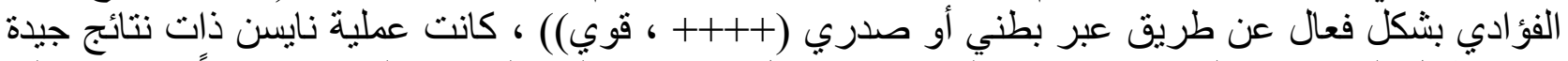

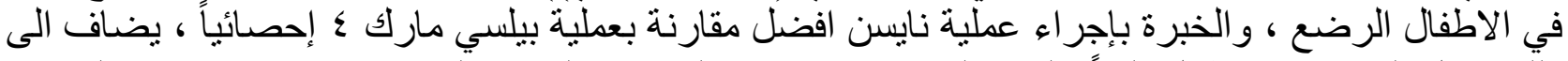

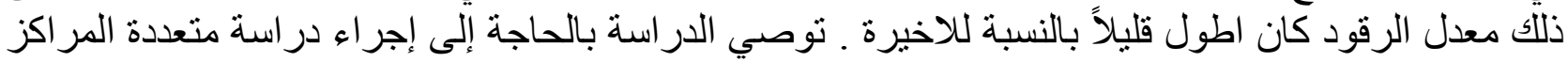

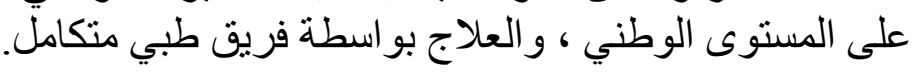

مفاتيع الكلمات : فتق الفتحة الفؤادية الولادي ، العضلة العاصرة العلوية للمريء ، عملية نايسن ، إجراء بيلسي مارك الر ابع. الرعات 